\title{
Propriedades mecânicas de resistência ao cisalhamento, compressibilidade, permeabilidade e a conformação do relevo no sudoeste do município de São Sedro do Sul - RS
}

\author{
Mechanical properties of shear resistance, compressibility, permeability and the form of \\ relief in southwest municipality of São Pedro do Sul - RS
}

\author{
Mauro Kumpfer Werlang e Arthur Piccolo
}

Universidade Federal de Santa Maria, Santa Maria, RS - Brasil

\begin{abstract}
Resumo
O trabalho foi desenvolvido numa área que abrange diferentes formações geológicas, sobre as quais evoluem relevos de dissecação e acumulação. Partiu-se do pressuposto de que o relevo e a conformação das vertentes do sudoeste do município de São Pedro do Sul, RS, devem-se a natureza do material sedimentar do topo das formações que ocorrem na área (areia fina, silte, argilas de baixa a média plasticidade, argilas arenosas e argilas siltosas) e, que a relação entre a configuração da drenagem e as formas de modelado do relevo, pode ser explicada pelo comportamento das propriedades de resistência ao cisalhamento, compressibilidade e permeabilidade. O objetivo do trabalho foi contribuir para o entendimento de parâmetros que expressam a configuração da rede hidrográfica, o modelado do relevo e a conformação de vertentes em diferentes formações geológicas da Bacia do Paraná, no sudoeste do município de São Pedro do Sul, RS. Os resultados obtidos indicam que as propriedades de resistência ao cisalhamento, compressibilidade e permeabilidade, influenciam o comportamento da rede de drenagem bem como a forma do perfil das vertentes, condicionando a evolução do relevo na área sudoeste do município de São Pedro do Sul, RS. O baixo relevo e a conformação de vertentes côncavas na área correspondente a formação Sanga do Cabral, contrasta com um relevo mais pronunciado em vertentes com formas convexas, nas áreas das formações Santa Maria $\left(T_{R} s m\right)$ e Caturrita $\left(T_{R} c\right)$, indicando relação com as propriedades de resistência ao cisalhamento, compressibilidade e permeabilidade do material sedimentar dessas formações geológicas.
\end{abstract}

Palavras-chave: formação geológica, propriedades mecânicas, conformação do relevo.

\begin{abstract}
The study was conducted in an area covering different geological formations, on which reliefs of dissection and accumulation evolves. It started from the assumption that the conformation of relief in the southwest of the city of São Pedro do Sul, RS, due to the nature of the sedimentary material (fine sand, silt, clay of low to medium plasticity, sandy clays and salty clays) from the top of the geological formations that occur in the area. It was also considered that the relation between the configuration of the drainage and the forms of the relief can be explained by the behavior of shear resistance properties, compressibility and permeability. In this sense, the objective of the work was to contribute to the understanding of parameters that express the configuration of the hydrographic system, the form of the relief and the conformation of strands in different geological formations of the Paraná Basin, in the southwest of São Pedro do Sul, RS. The results indicate that the properties of shear strength, compressibility and permeability influence the behavior of the drainage system as well the profile shape of slopes, affecting the relief evolution in the southwest area of São Pedro do Sul, RS. The low relief and the conformation of the concave slopes in the Sanga do Cabral formation area contrasts with a more pronounced relief in convex shapes, in the formations areas of Santa Maria $\left(T_{R} s m\right)$ and Caturrita $\left(T_{R} c\right)$, indication relation with the properties of shear strength, compressibility and permeability of sedimentary material from these geological formations.
\end{abstract}

Key words: geological formation, mechanical properties, relief conformation. 


\section{Introdução}

As propriedades de resistência ao cisalhamento, compressibilidade e permeabilidade podem apresentar diferenças, no mesmo estado de compacidade, para solos distintos. Podem, igualmente, apresentar diferenças acentuadas, dependendo da granulometria e formato dos grãos. A resistência ao cisalhamento é uma propriedade que os solos possuem de resistirem ao deslizamento de uma seção em relação à outra próxima. $\mathrm{O}$ entrosamento entre os grãos pode ser caracterizado pela compacidade ou pelo índice de vazios inicial da amostra. Observa-se que com uma maior aproximação e entrosamento das partículas, ocorre um aumento da coesão e do atrito interno, proporcionando aumento da resistência ao cisalhamento. Com uma redução do índice de vazios, a capacidade de absorção de água e a possibilidade de haver percolação diminuem substancialmente. Portanto, compactação, compressibilidade e cisalhamento são propriedades dinâmicas e correlacionam-se entre si.

O trabalho foi desenvolvido em uma área que abrange diferentes formações geológicas, sobre as quais evoluem relevos de dissecação e acumulação. Partiu-se do pressuposto que a área correspondente a Formação Sanga do Cabral apresenta um baixo relevo quando comparada às áreas da Formação Santa Maria (membro Alemoa) e Formação Caturrita. Considerou-se que esse pressuposto esteja relacionado à natureza do material sedimentar no topo dessas formações (areia fina, silte, argilas de baixa a média plasticidade, argilas arenosas e argilas siltosas). Também se considerou que a relação entre a configuração da drenagem (grau de entalhamento dos talvegues e dimensão interfluvial) e as formas de modelado do relevo (modelados de acumulação e dissecação) pode ser explicada pelo comportamento das propriedades de resistência ao cisalhamento, compressibilidade e permeabilidade, cuja relação de causa e efeito está refletido nessas formas ou nos conjuntos de formas.
Nessa perspectiva, o objetivo do trabalho foi contribuir para o entendimento de parâmetros que expressam a configuração da rede hidrográfica, o modelado do relevo e a conformação de vertentes em diferentes formações geológicas da Bacia do Paraná, no sudoeste do município de São Pedro do Sul, RS. Buscou-se ainda, assinalar uma relação de causa e efeito nas quais influem as propriedades de resistência ao cisalhamento, compressibilidade e permeabilidade para a conformação do relevo do sudoeste do município de São Pedro do Sul, RS.

\section{Procedimentos Metodológicos}

\subsection{Descrição geral da área}

A área base de estudo está situada na região central do estado do Rio Grande do Sul, no sudoeste do município de São Pedro do Sul, entre as coordenadas geográficas $29^{\circ} 36^{\prime} 24^{\prime \prime}$ e $29^{\circ} 45^{\prime} 09^{\prime \prime}$ de latitude sul; $54^{\circ} 15^{\prime} 30^{\prime \prime}$ e $54^{\circ} 29^{\prime} 36^{\prime \prime}$ de longitude oeste. Abrange aproximadamente $296 \mathrm{~km}^{2}$ e está assentada sobre litologias do Grupo Rosário do Sul: Formação Sanga do Cabral, Formação Santa Maria (membro Passo das Tropas e membro Alemoa) e Formação Caturrita, Coberturas Terciárias, além de terraços fluviais e sedimentos atuais do Quaternário (Andreis et al., 1982). O membro Passo das Tropas é o membro inferior da unidade litoestratigráfica Formação Santa Maria, representada por sedimentos grósseos. Sotoposto ocorre a Formação Sanga do Cabral. O membro Alemoa constitui o membro superior da Formação Santa Maria, onde a litologia típica está representada por lamitos e siltitos argilosos. As litologias mais representativas da Formação Caturrita, conforme Bortoluzzi (1974) constituem-se de camadas de arenitos finos até médios com composição quartzosa, que se intercalam com camadas de siltitos arenosos de espessura menor, enquanto arenitos de textura mais grosseira são comuns junto à base. As coberturas Terciárias estão constituídas por

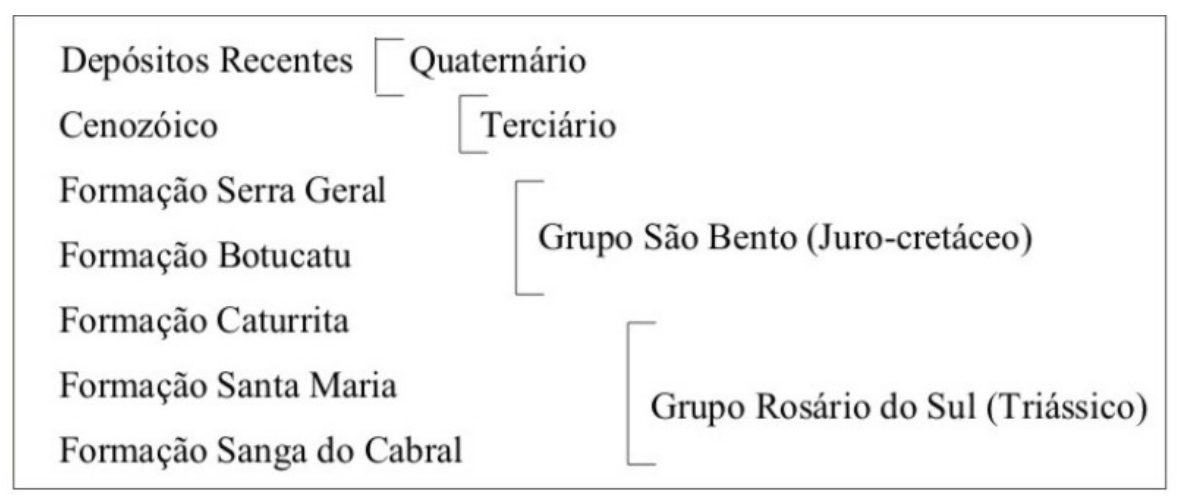

Figura 1. Posição das formações geológicas que ocorrem no sudoeste do município de São Pedro Sul, RS. Fonte: Adaptado de Andreis et al (1982). 


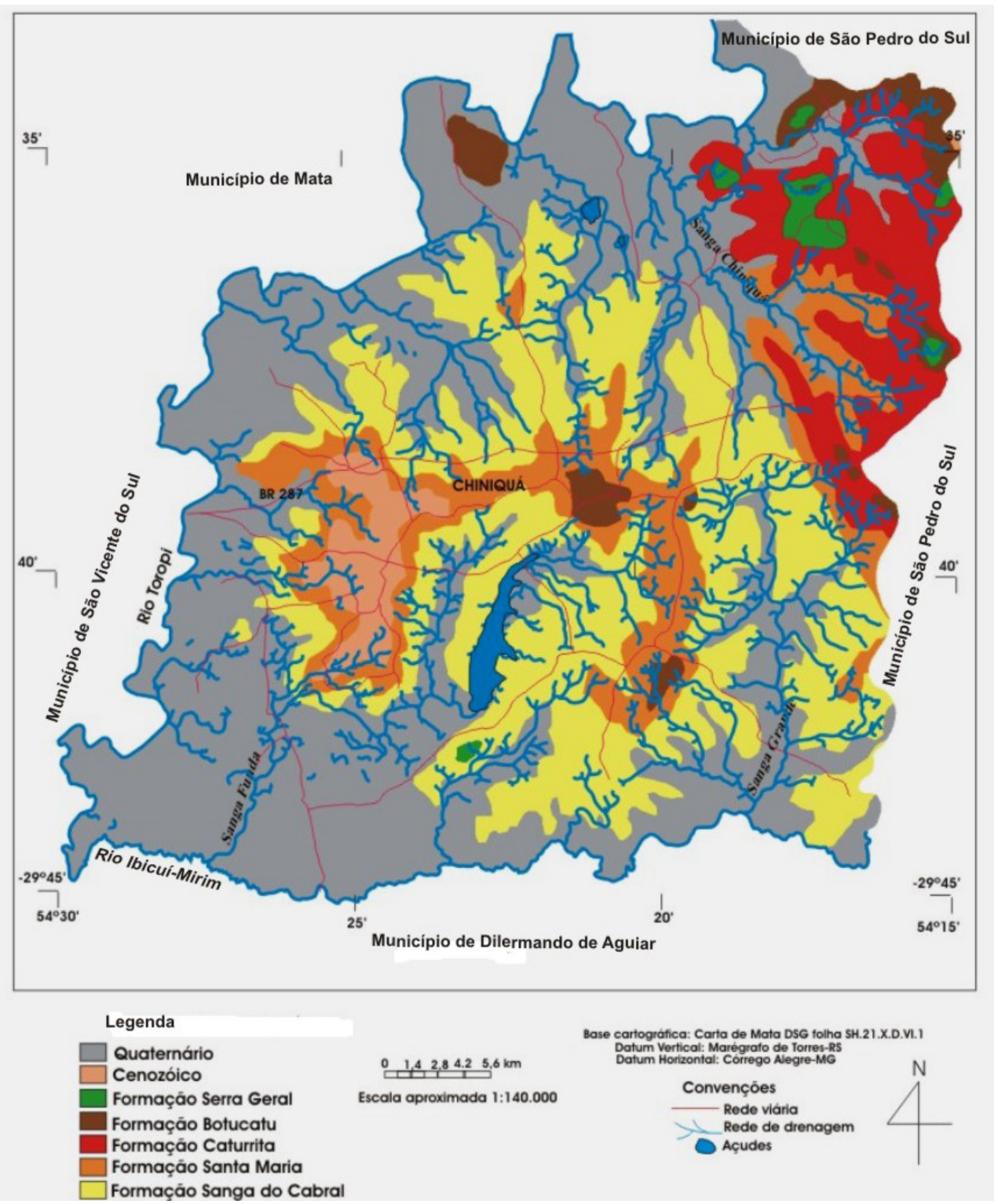

Figura 2. Mapa das formações geológicas no sudoeste do município de São Pedro Sul, RS.

Fonte: Werlang (2004).

materiais retrabalhados a partir das formações que ocorrem na área. Os depósitos Quaternários, pelo fato de serem originários da dinâmica presente e pré-atual de acumulação sedimentar, encontram-se associados aos atuais agentes de sedimentação. A figura 1 mostra um esquema da posição das formações geológicas e, a figura 2 traz o mapa com as formações geológicas que ocorrem no sudoeste do município de São Pedro Sul, RS.

Em relação à geomorfologia, a área está situada na Depressão Periférica Sul-rio-grandense, na transição para os Planaltos e Chapadas da Bacia Sedimentar do Paraná (Ross,1996). A figura 3 localiza o município de São Pedro do Sul em relação à geomorfologia, no estado do Rio Grande do Sul. As áreas das planícies aluviais estão constituídas por sedimentos recentes (Quaternário). As coxilhas aparecem tanto em setores isolados como em conjuntos de sequências, constituindo as áreas mais elevadas do setor sudoeste do município de São Pedro do Sul. Em alguns pontos, formam-se colinas alongadas que se apresentam na forma de encostas rampeadas, onde ocorrem fenômenos de erosão e movimentos de massa. Nessas áreas, predominam solos bem drenados como, por exemplo, os Argissolos. Nos terraços e planícies fluviais, ocorrem solos e associações de solos imperfeitamente a mal drenados, como os Plintossolos, Planossolos e Gleissolos. A figura 4 ilustra o perfil de um Argissolo e a figura 5 um Plintossolo que ocorre na área da Formação Sanga do Cabral. A figura 6 mostra o aspecto de uma área onde ocorrem Planossolos e Gleissolos. 


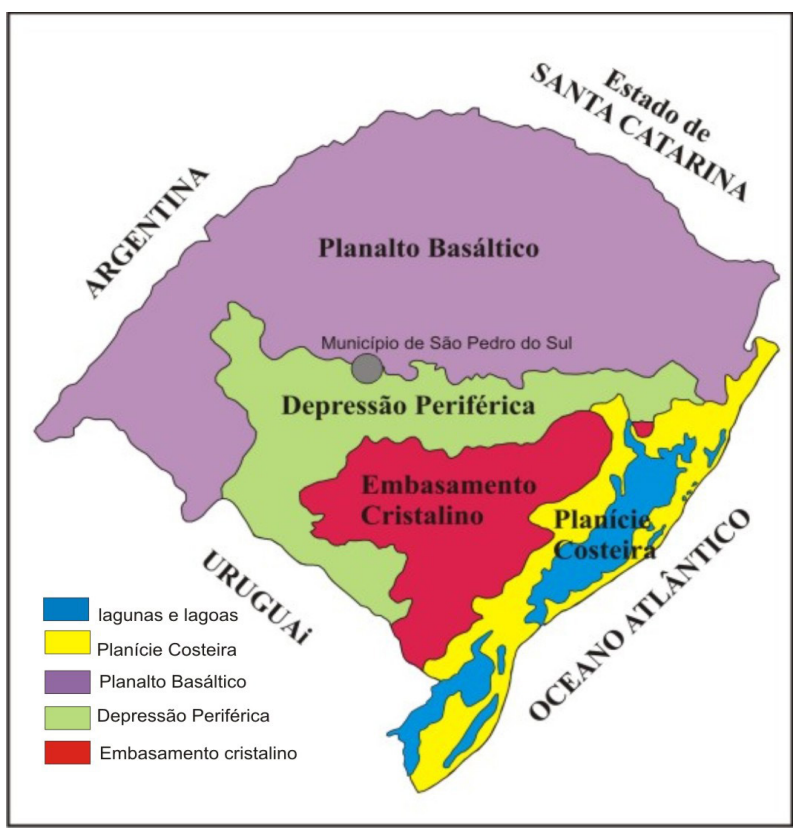

Figura 3. Localização do município de São Pedro do Sul em relação às províncias geomorfológicas do estado do Rio Grande do Sul.

Fonte: http://www.ufrgs.br/paleotocas/RioGrandedoSul.htm. Acesso:24 ago.2013 (adaptado)

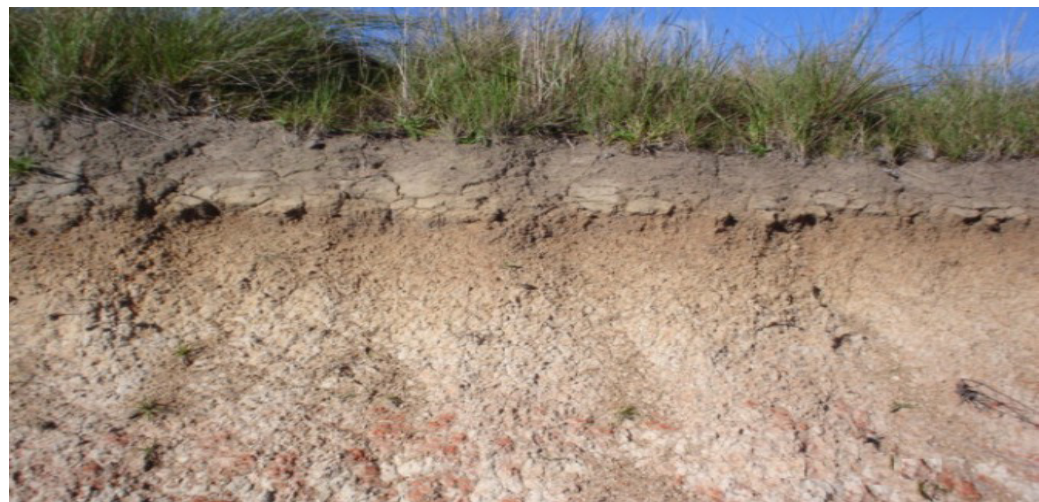

Figura 4. Aspecto do perfil de um Argissolo Amarelo que ocorre na área de estudo (localidade de Chiniquá), cujo material de origem é a Formação Sanga do Cabral.

Fonte: Trabalho de campo, julho de 2012.

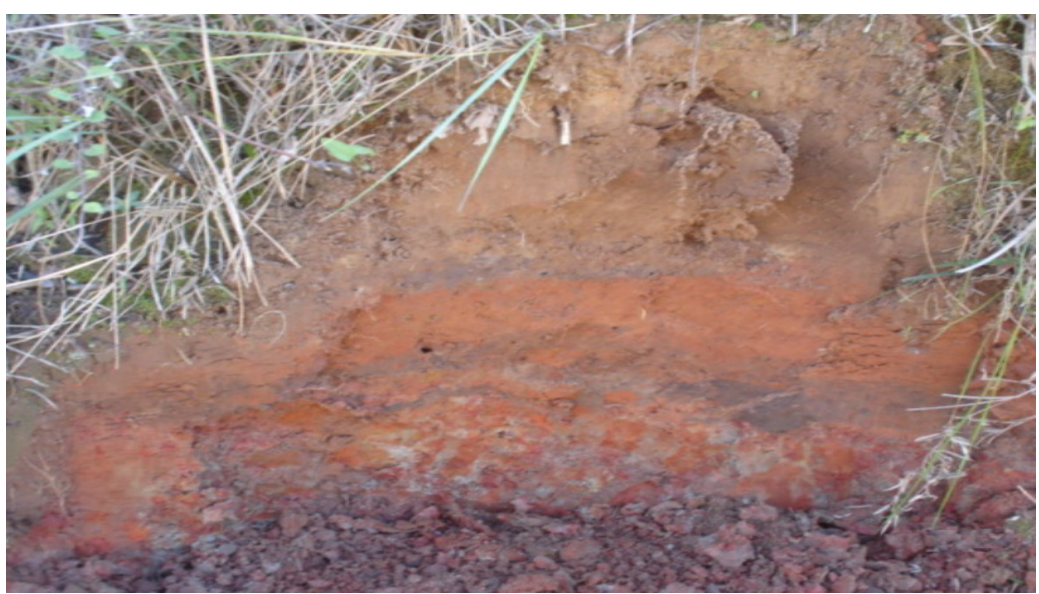

Figura 5. Aspecto do perfil de um Plintossolo que ocorre na área de estudo (localidade de Chiniquá), cujos materiais de origem predominantes são da Formação Sanga do Cabral.

Fonte: Trabalho de campo, julho de 2012. 


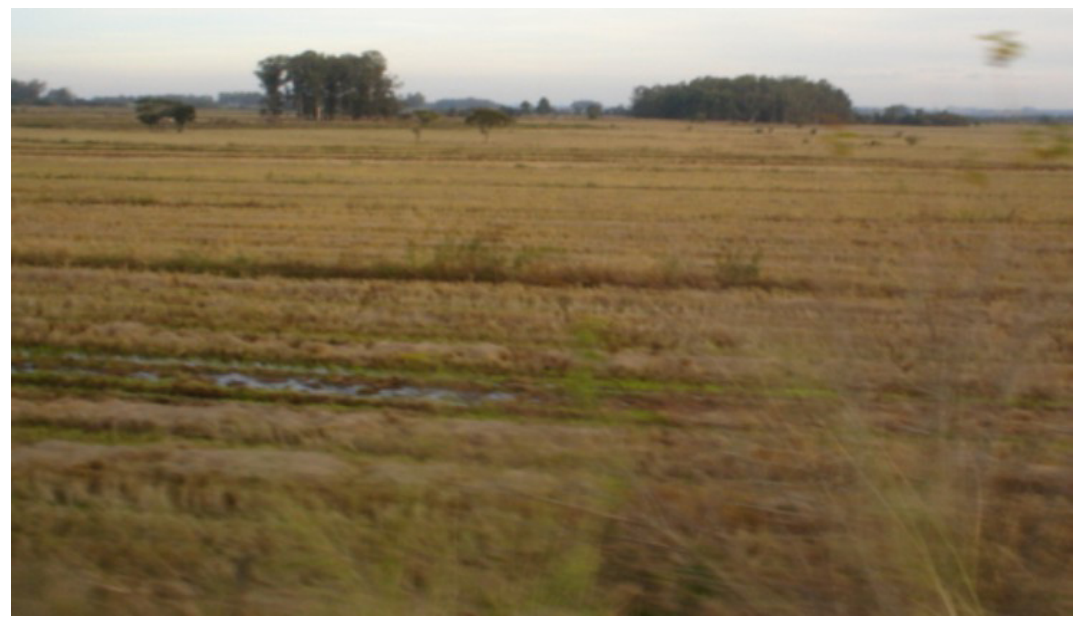

Figura 6. Aspecto do relevo em uma área de acumulação onde ocorrem Planossolos e Gleissolos (localidade de Chiniquá), cujo material de origem são sedimentos Terciários e Quaternários.

Fonte: Trabalho de campo, julho de 2012.

A área pertence ao sistema hidrográfico IbicuíMirim/Toropi (parte da área pertence à sub-bacia do rio Ibicuí-Mirim e a outra porção é pertencente à sub -bacia do rio Toropi). Além desses rios, constituem-se como cursos fluviais importantes o Arroio Chiniquá e a Sanga Funda, além de inúmeros outros canais fluviais que são responsáveis pelo modelado de dissecação dos interflúvios e pelo entalhamento dos talvegues.

No que se refere à vegetação e ao uso da terra, face à ocupação com atividades agrícola e pecuária, a área em estudo sofreu significativas alterações na cobertura original da vegetação. Nela predominam pastagens e lavouras com o cultivo de arroz, soja e milho. Situa-se, de acordo com Vieira (1984), no domínio dos campos com capões e matas galerias. Apesar de estar dedicada à pecuária e agricultura, apresentando uma cobertura de gramíneas e pastagens entremeadas com lavouras, existem pontos onde ocorre a vegetação remanescente da cobertura vegetal original (floresta estacional decidual) que aparece em formas ciliares representadas por capões e mata galeria. A figura 7 mostra o aspecto da área onde predomina uma cobertura de gramíneas e pastagem plantada e, a figura 8, ilustra uma visualização aérea da área de estudo onde aparecem os campos com capões e matas galerias.

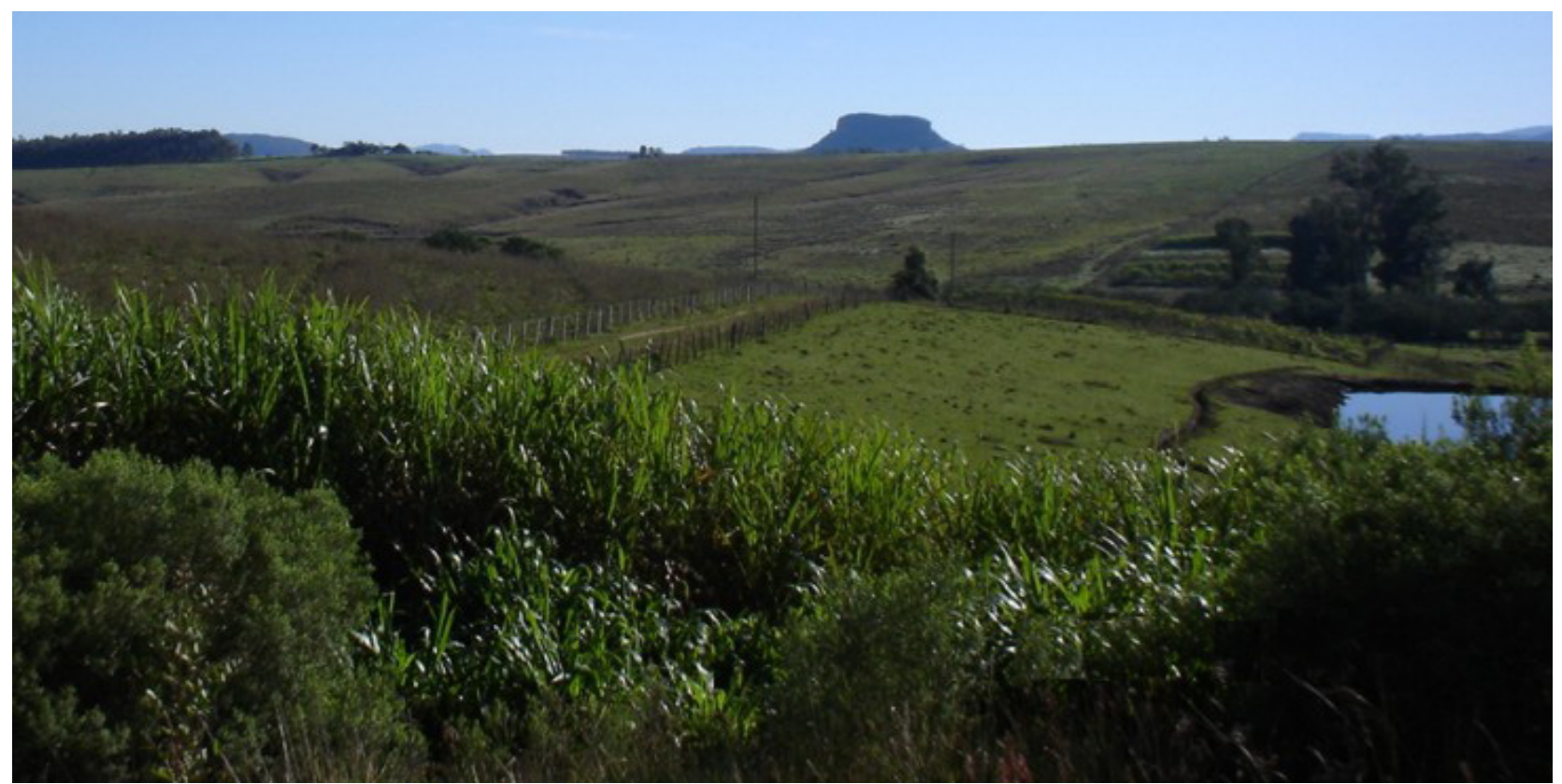

Figura 7. Aspecto da vegetação da área de estudo, na localidade de Carpintaria, onde predomina uma cobertura de gramíneas e presença de lavoura.

Fonte: Trabalho de campo, janeiro de 2013. 


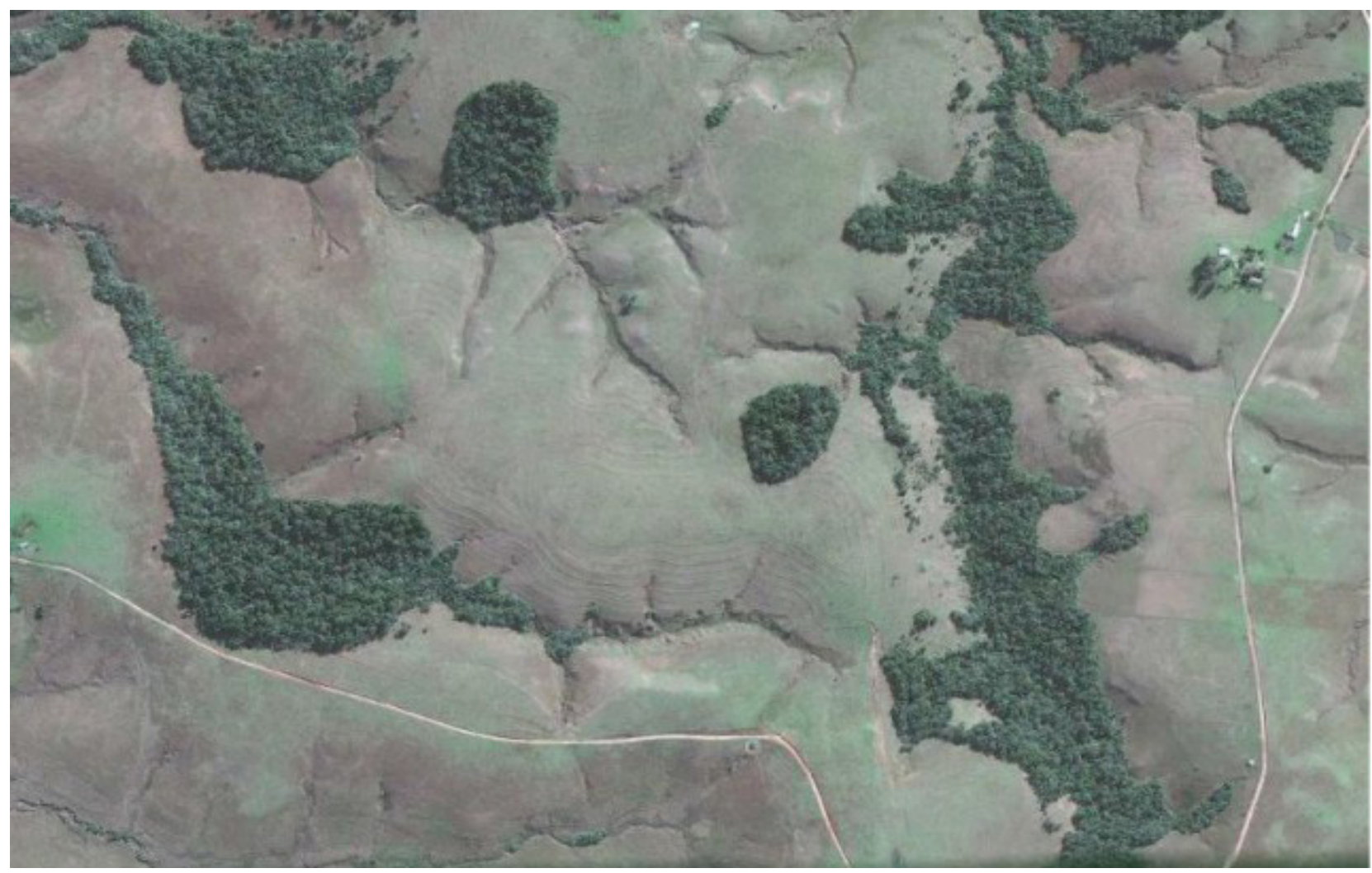

Figura 8. Aspecto da área de estudo, na localidade de Chiniquá, a partir de uma visão aérea, onde aparecem os campos com capões e as matas galerias.

Fonte: Google Earth. Acesso: 24 ago.2013.

A região de São Pedro do Sul, conforme a classificação climática de Köppen (1948) corresponde ao clima mesotérmico brando Cfa (temperado quente) apresentando como caraterísticas invernos frios, com temperatura média do mês mais frio entre $13^{\circ} \mathrm{C}$ e $15^{\circ} \mathrm{C}$ e média das mínimas entre $8^{\circ} \mathrm{C}$ e $10^{\circ} \mathrm{C}$. Os verões são quentes, com temperatura média do mês mais quente superior a $24^{\circ} \mathrm{C}$, média das máximas variando entre $28^{\circ} \mathrm{C}$ e $32^{\circ} \mathrm{C}$ e as máximas absolutas oscilando em torno dos $39^{\circ} \mathrm{C}$. As temperaturas médias anuais situam-se entre $16^{\circ} \mathrm{C}$ e $20^{\circ} \mathrm{C}$. As precipitações são regulares durante todo o ano, não apresentando estação seca, com índices pluviométricos anuais entre $1.500 \mathrm{~mm}$ e $1.600 \mathrm{~mm}$. Os ventos predominantes são de leste e sudeste.

\subsection{Métodos}

Para o desenvolvimento do trabalho adotouse a orientação metodológica da proposta de análise sistêmica da paisagem (Sochava, 1972; Bertrand, 1968, 1971; Monteiro, 2000) e dos níveis de tratamento definidos por Ab'Saber (1969). Classificados em grupos epistemológicos os métodos podem ser indutivos, dedutivos, hipotético-dedutivo, dialético e fenomenológico. Para realização deste trabalho, fez-se uso do método dedutivo, acreditando-se ser esta uma das formas que permite uma maior proximidade da realidade com a pesquisa. Proposto porPopper, consistena adoçãoda seguintelinhaderaciocínio, conformeGil (1999, p.30):

“quando os conhecimentos disponíveis sobre determinado assunto são insuficientes para a explicação de um fenômeno, surge o problema. Para tentar explicar as dificuldades expressas no problema, são formuladas conjecturas ou hipóteses. Das hipóteses formuladas, deduzem-se conseqüências que deverão ser testadas ou falseadas. Falsear significa tornar falsas as conseqüências deduzidas das hipóteses. Enquanto no método dedutivo se procura a todo custo confirmar a hipótese, no método hipótetico-dedutivo, ao contrário, procuram-se evidências empíricas para derrubá-la" .

As propriedades de resistência ao cisalhamento, compressibilidade e permeabilidade podem apresentar diferenças, no mesmo estado de compacidade, para solos distintos (Holtz; Kovacs, 1981). Podem apresentar diferenças acentuadas, dependendo da granulometria e formato dos grãos. Nesse sentido, o 
ângulo de atrito do solo é importante e é influenciado por diversos fatores, onde a compacidade do solo é um dos fatores mais influentes. Assim, o entrosamento entre os grãos pode ser caracterizado pela compacidade ou pelo índice de vazios inicial da amostra, que se for pouco densa, apresentará maior valor de índice de vazios que o de uma areia compacta ou densa.

Vargas (1977) observa alguns fatores que influenciam na resistência ao cisalhamento das areias, entre eles: o tamanho das partículas (areias grossas possuem ângulo de atrito maior que as areias finas); a forma dos grãos (areias com grãos angulares apresentam maior resistência que aquelas que possuem grãos de forma regular) e a distribuição granulométrica (quanto mais bem distribuídas granulometricamente a areia, melhor o entrosamento existente e, conseqüentemente, maior o ângulo de atrito).

A resistência ao cisalhamento é, portanto, a propriedade que os solos possuem de resistir ao deslizamento de uma seção em relação a outra próxima. Essa resistência cresce com a pressão normal ao plano de cisalhamento. A resistência ao cisalhamento de um solo em qualquer direção é a tensão de cisalhamento máxima que pode ser aplicada à estrutura do solo naquela direção. Quando esse máximo é atingido, diz-se que o solo rompeu, tendo sido totalmente mobilizada a resistência do solo. Envolve duas componentes: atrito e coesão. Esses dependem da umidade e do índice de vazios. O atrito é função da interação entre duas superfícies na região de contato. A atração química entre partículas (óxidos, hidróxidos e argilas) pode provocar a existência de coesão (Vargas, 1977; Holtz e Kovacs, 1981). No que se refere às argilas, a coesão é resultante de forças de natureza eletroquímica, geradas entre as partículas, de maneira que sua aproximação, resultante da compactação, ou seja, de um menor índice de vazios, tende a aumentá-la. No entanto, diminui com o aumento da umidade, que, pela maior presença de água nos interstícios, tende a diminuir as forças de natureza eletroquímica. $\mathrm{O}$ aumento do atrito interno dependerá do atrito gerado entre as partículas e do seu entrosamento. Entende-se que a aproximação dos grãos e o seu melhor arranjo são resultantes de um baixo índice de vazios e de um teor de água que não cause o distanciamento entre elas. Maior aproximação e entrosamento das partículas, ocasionando um aumento da coesão e do atrito interno, proporcionam aumento da resistência ao cisalhamento. Com a redução do índice de vazios, a capacidade de absorção de água e a possibilidade de haver percolação diminuem substancialmente. Portanto, compactação, compressibilidade e cisalhamento são propriedades dinâmicas e correlacionam-se entre si (Vargas, 1977; Caputo, 1981; Dias Junior, 1999; Silva, 1999; Silva et al., 2000; Silva et al., 2002).

\subsection{Procedimentos metodológicos}

Foram selecionados, para o estudo, quatro perfis representativos das formações geológicas: $T_{R} s m$ (Formação Santa Maria); $T_{R}$ rs (Formação Sanga do Cabral); $T_{R} C$ (Formação Caturrita) e, Cen (Coberturas do Terciário). As figuras 9, 10, 11 e 12 ilustram, respectivamente, afloramentos dessas formações de onde foram coletadas amostras.

A partir dos perfis selecionados foram coletadas amostras indeformadas em 19 pontos amostrados, com três repetições, totalizando 57 amostras. Essas amostras serviram para os ensaios de compressibilidade e cisalhamento e distribuição do tamanho de poros. Nesses perfis, também foram realizados ensaios de infiltração em pontos correspondentes

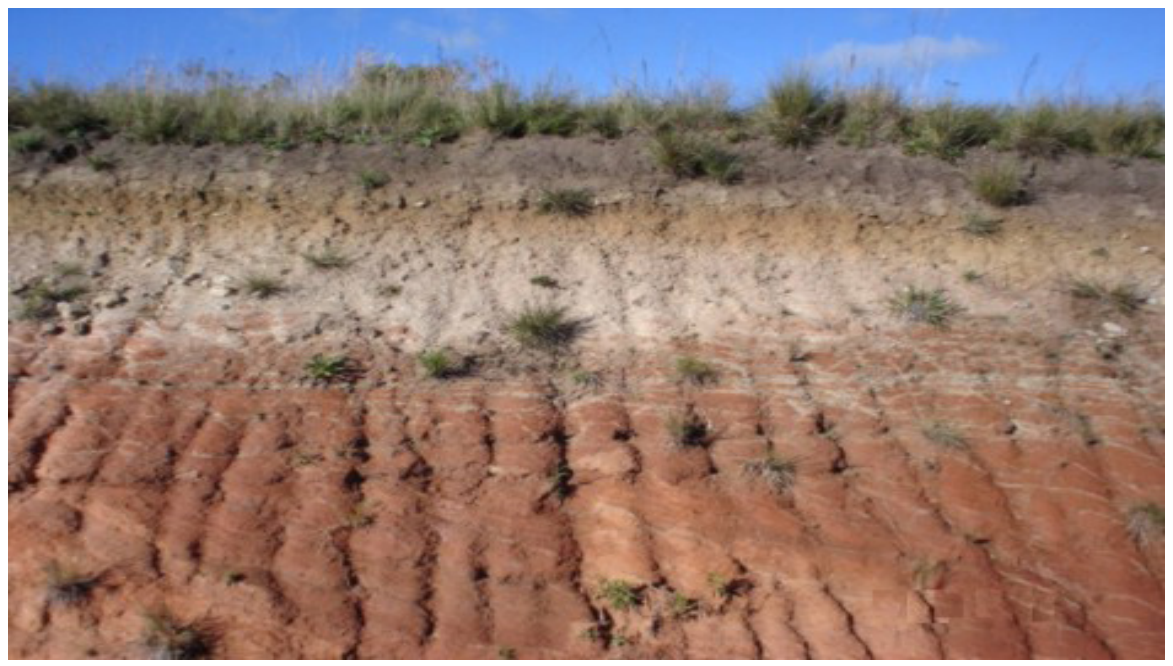

Figura 9. Localidade de Chiniquá - Aspecto do afloramento da Formação Santa Maria de onde foram coletadas amostras. Fonte: Trabalho de campo, julho de 2012. 


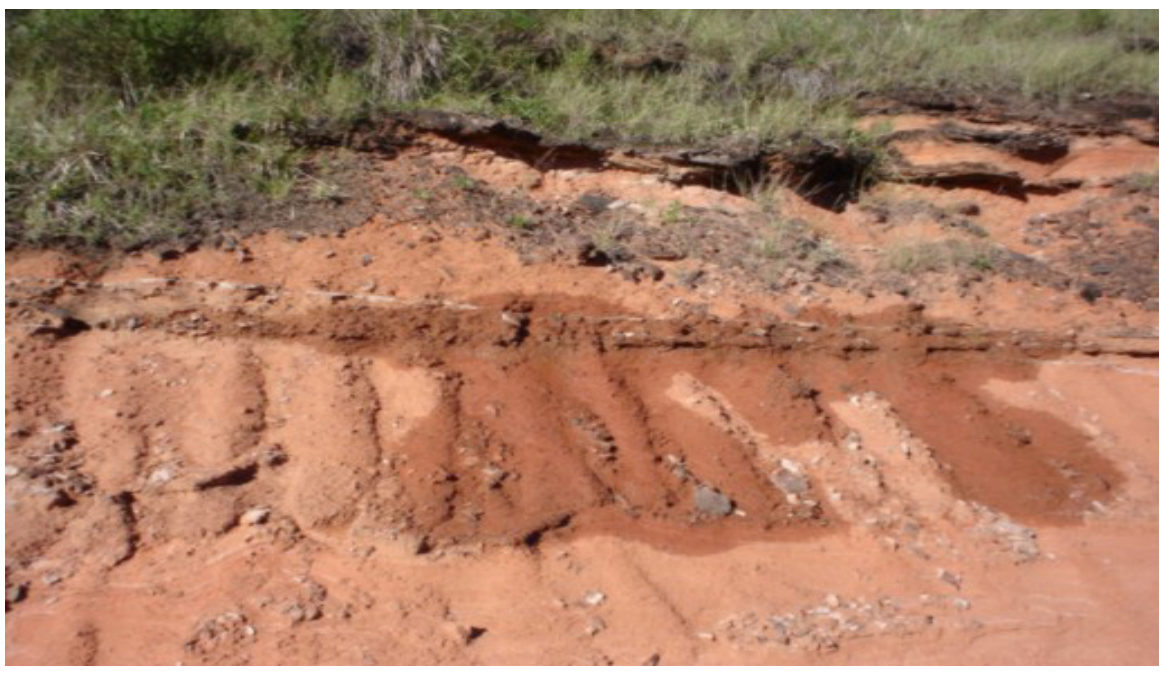

Figura 10. Aspecto do afloramento da Formação Sanga do Cabral e de onde foram coletadas amostras - Localidade de Chiniquá. Fonte: Trabalho de campo, julho de 2012.

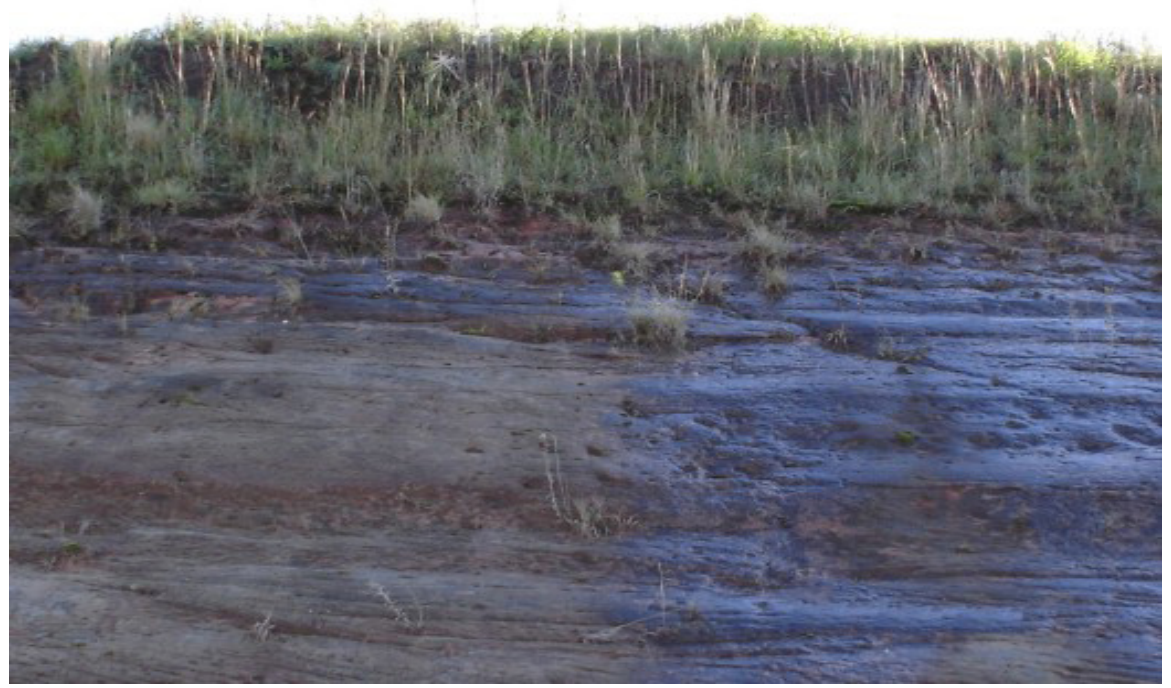

Figura 11. Localidade de Carpintaria - Aspecto do afloramento da Formação Caturrita de onde foram coletadas amostras. Fonte: Trabalho de campo, julho de 2012.

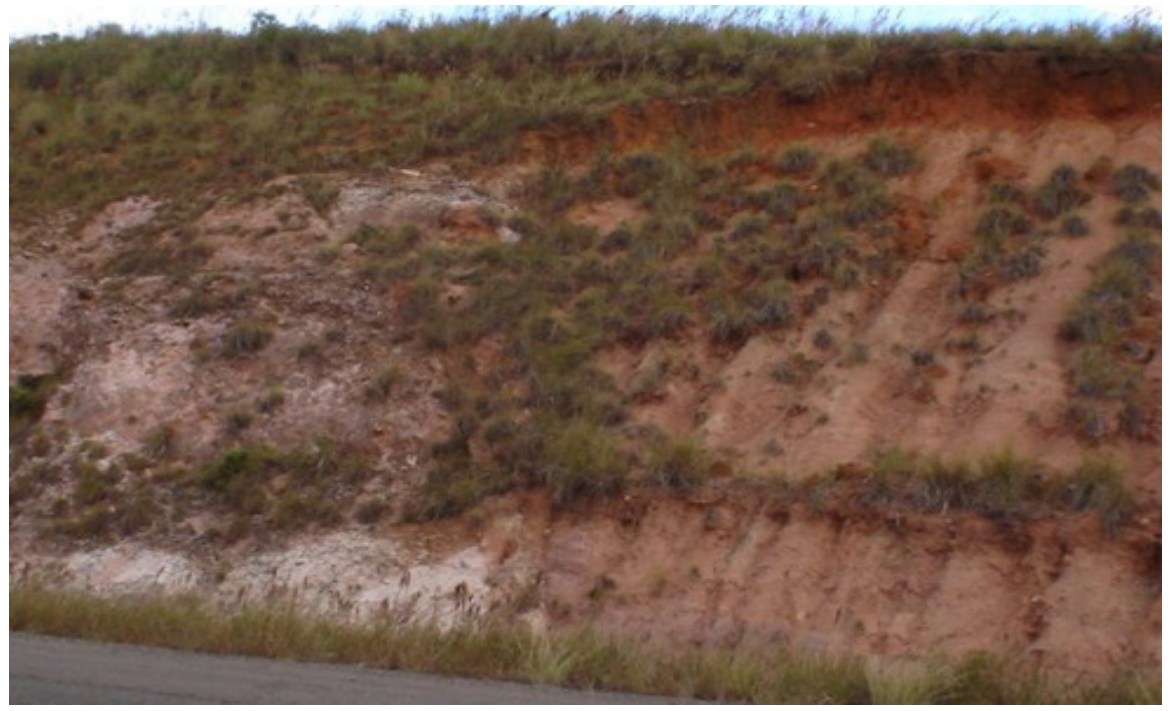

Figura 12. Localidade de Chiniquá - Aspecto do afloramento das Coberturas do Terciário de onde foram coletadas amostras. Fonte: Trabalho de campo, julho de 2012. 
ao topo da formação (camada $\mathrm{R}$ ) respectiva a cada formação geológica.

Para a determinação da distribuição do tamanho de poros, as amostras com estrutura preservada foram coletadas em anéis de 5,54 cm de diâmetro e $2,0 \mathrm{~cm}$ de altura, nos quatro perfis selecionados, relativos às formações que ocorrem na área. As amostras foram saturadas e posteriormente acondicionadas na mesa de tensão $(10 \mathrm{~cm}$ e $60 \mathrm{~cm})$ e na panela de pressão (0,33 bar e um bar), para a obtenção da porosidade e tamanho e distribuição de poros. A determinação da microporosidade se deu pela diferença entre o peso da amostra após ser submetida a uma tensão de $60 \mathrm{~cm}$ de coluna de água e o peso da amostra seca a $105^{\circ} \mathrm{C}$, dividido pelo volume da amostra. A macroporosidade foi obtida pela diferença entre a percentagem de saturação e a micro porosidade. Para se chegar ao raio dos poros, foi utilizada a foi utilizada a expressão (Hillel, 1980; Fernandes et al, 1983):

$$
h=2 \sigma / \gamma g r
$$

Onde: $\sigma$ é a tensão superficial da água, em função da temperatura $\left(71,9 \mathrm{~g} \mathrm{~s}^{-2}\right.$ a $\left.25^{\circ} \mathrm{C}\right) ; \gamma$ é a densidade da água na temperatura observada $\left(0,99707 \mathrm{~g} \mathrm{~cm}^{-3}\right.$ a 25 $\left.{ }^{\circ} \mathrm{C}\right) ; g$ é a aceleração da gravidade $\left(981 \mathrm{~cm} \mathrm{~s}^{-2}\right)$ e, $r$ é o raio do poro, de onde se obtém que:

$$
r=2 \sigma / \gamma g h
$$

A resistência ao cisalhamento da amostra foi determinada segundo metodologia descrita em Caputo, (1981). A envoltória de resistência ao cisalhamento do solo, pode ser expressa pela equação de Coulomb:

$$
\tau=c+\sigma \operatorname{tg} \phi
$$

Nessa equação, os parâmetros $c$ e $f$ representam, respectivamente, a coesão entre as partículas do solo e o coeficiente de atrito entre as mesmas. Esses parâmetros são características intrínsecas do material, pois são dependentes de outras propriedades e atributos como, textura, estrutura, teor de matéria orgânica, densidade, mineralogia e conteúdo de água (Lebert; Horn, 1991). O ensaio foi realizado com a aplicação de uma carga estática vertical de 50, 100 e $200 \mathrm{kPa}$, em amostras com estrutura preservada, de dimensões $5,1 \mathrm{~cm} \times 5,1 \mathrm{~cm} \times 2,0 \mathrm{~cm}$ equilibradas na tensão de 100 $\mathrm{kPa}$. A carga vertical foi aplicada durante 5 minutos, após os quais se iniciou o ensaio.

Para determinar a curva de compressão, as amostras com estrutura preservada foram coletadas em anéis de 5,54 cm de diâmetro e 2,0 cm de altura, saturadas por 24 horas e, após, submetidas a uma tensão de um bar e levadas ao ensaio de compressão uniaxial. Aplicaram-se pressões estáticas e sucessivas (zero, 12,5; 25; 50; 100; 200; 400; 800 e $1600 \mathrm{kpa}$.) durante carregamentos de intervalos de tempo determinados, conforme Silva (1999). Após a realização do ensaio, a curva de compressão do solo foi determinada pelo método de Casagrande (Holtz; Kovacs, 1981), com o auxílio do aplicativo Compress 1.0 (Reinert, 2003).

Para a determinação do coeficiente de infiltração, foram realizados três ensaios em pontos da camada $\mathrm{R}$, representativas de cada formação geológica. Utilizou-se de um cilindro de $15 \mathrm{~cm}$ de altura $\left(\mathrm{h}_{\mathrm{cil}}\right)$ e cinco $\mathrm{cm}$ de diâmetro $\left(\mathrm{d}_{\text {cil }}\right)$, cravado cinco centímetros na camada $\mathrm{R}$ (procurou-se, para fins de execução do ensaio, posições na camada $R$ que permitiram cravar o cilindro), mantendo-se uma lâmina d'água de $10 \mathrm{~cm}$ acima do solo. A entrada de água foi lida, através de uma régua, em centímetros em intervalos de $30^{\prime \prime}, 1^{\prime}$, $3^{\prime}, 4^{\prime}, 5^{\prime}$, e após, intervalos constantes de $10^{\prime}$ até que a vazão tenha se tornado constante. A vazão (Q) pôde ser obtida dividindo-se a variação de volume $(\Delta V)$ por um intervalo de tempo $(\Delta T)$. Para o cálculo do coeficiente de infiltração, além de procurar-se a vazão em si, foi necessário encontrar um valor constante. Assim, foi plotado em um gráfico, volume infiltrado versus tempo e encontrado um trecho retilíneo, o qual representa a vazão constante. O coeficiente angular deste trecho retilíneo representa a vazão constante (Netto; Avelar (1996). A partir dos valores de $\Delta V$ e $\Delta T$ extraídos do gráfico tem-se:

$$
\mathrm{Q}=\Delta V / \Delta T
$$

(equação 4)

Dividindo-se o resultado pela área do cilindro $\left(\mathrm{A}_{\text {cil }}\right)$ cravado na camada $\mathrm{R}$, expresso em $\mathrm{cm}^{2}$, obtém-se a capacidade de infiltração $(\mathrm{CI})$ através da equação:

$$
\mathrm{CI}=\mathrm{Q} / \mathrm{A}_{\text {cil }}=\mathrm{Q} /\left(\pi \times\left(\mathrm{d}_{\text {cil }} / 2\right)^{2}\right) \quad \text { (equação 5) }
$$

\section{Resultados e Discussão}

O comportamento da resistência ao cisalhamento (tabela 1) revela maiores valores de coesão para os materiais relativos a Formação Sanga do Cabral ( $\left.\mathrm{T}_{\mathrm{R}} \mathrm{rs}\right)$. Essa constatação, aliada ao ângulo de atrito interno e a tensão cisalhante de ruptura, leva ao entendimento de que essa área reflete o resultado da ação do desgaste sobre materiais que oferecem maior resistência ao cisalhamento. Daí resulta padrões de 
drenagem com maior comprimento do canal principal e menor densidade de drenagem. Também influi na conformação da paisagem no sentido de configurar um baixo relevo, com formas côncavas, caracterizado na área de ocorrência da Formação Sanga do Cabral
$\left(\mathrm{T}_{\mathrm{R}} \mathrm{rs}\right)$. Para as áreas relativas às formações Santa Maria $\left(T_{R} s m\right)$ e Caturrita $\left(T_{R} c\right)$, bem como para as coberturas do Terciário (Cen), ocorre menor coesão, configurando um relevo com topografia mais movimentada e formas convexas nessas áreas.

Tabela 1. Resultados obtidos a partir dos ensaios de cisalhamento direto para os perfis representativos das formações geológicas no sudoeste do município de São Pedro do Sul, RS.

\begin{tabular}{|c|c|c|c|c|c|c|c|}
\hline \multirow{2}{*}{$\begin{array}{l}\text { Formação } \\
\text { geológica }\end{array}$} & \multirow{2}{*}{$\begin{array}{l}\text { Umidade equilibrada } \\
\text { a } 1 \text { bar (\%) }\end{array}$} & \multirow{2}{*}{$\begin{array}{l}\text { Densidade } \\
\gamma \mathrm{d}\left(\mathrm{gcm}^{-3}\right)\end{array}$} & \multirow{2}{*}{$\begin{array}{l}\text { Coesão } \\
\mathrm{C}(\mathrm{kPa})\end{array}$} & \multirow{2}{*}{$\begin{array}{l}\text { Ângulo de } \\
\text { atrito }(\phi)\end{array}$} & \multicolumn{3}{|c|}{$\begin{array}{l}\text { Tensão cisalhante } \\
\text { de ruptura (kPa) }\end{array}$} \\
\hline & & & & & 50 & 100 & 200 \\
\hline $\mathrm{T}_{\mathrm{R}} \mathrm{rs}$ & 18,25 & 1,44 & 48,80 & 29,39 & 79,4 & 101,5 & 162,7 \\
\hline $\mathrm{T}_{\mathrm{R}} \mathrm{C}$ & 17,78 & 1,40 & 12,70 & 35,20 & 46,2 & 85,9 & 152,9 \\
\hline $\mathrm{T}_{\mathrm{R}} \mathrm{sm}$ & 17,42 & 1,47 & 12,25 & 36,54 & 52,0 & 89,8 & 163,3 \\
\hline Cen & 17,26 & 1,49 & 8,20 & 45,36 & 41,6 & 4,3 & 193,9 \\
\hline
\end{tabular}

$\mathrm{T}_{\mathrm{R}} \mathrm{sm}=$ Formação Santa Maria; $\mathrm{T}_{\mathrm{R}} \mathrm{rs}=$ =Formação Sanga do Cabral; $\mathrm{T}_{\mathrm{R}} \mathrm{c}=$ =Formação Caturrita; Cen= Coberturas do Terciário. Fonte: Ensaios em laboratório, 2012.
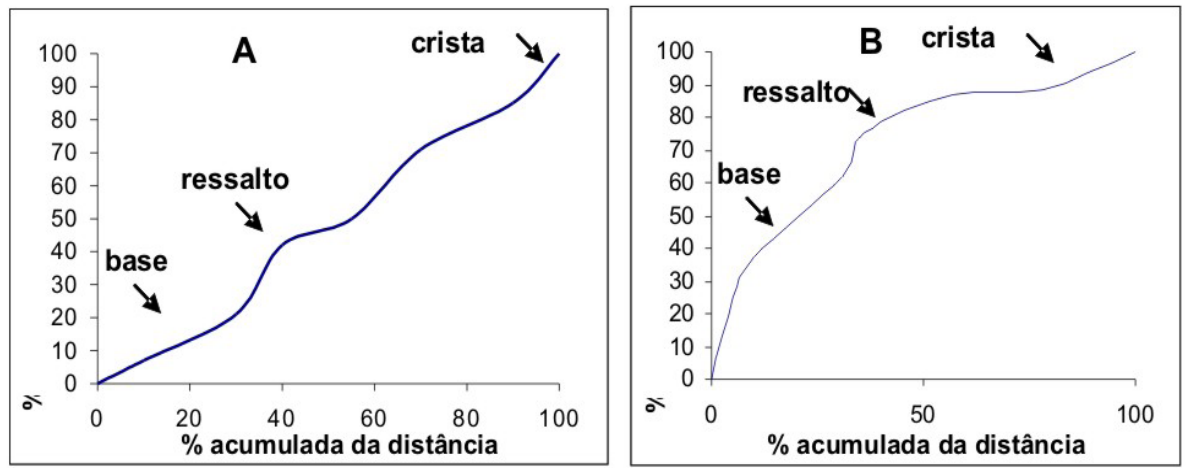

Figura 13. Padrões representativos do perfil em vertentes mostrando a presença de um pequeno ressalto topográfico evidenciando a ação da erosão diferencial sobre a vertente. Em A, tem-se a conformação de um perfil côncavo (forma predominante nas vertentes sobre a Formação Sanga do Cabral) e, em B um perfil convexo (forma predominante nas vertentes sobre as formações Santa Maria e Caturrita).

Fonte: Werlang, (2004).

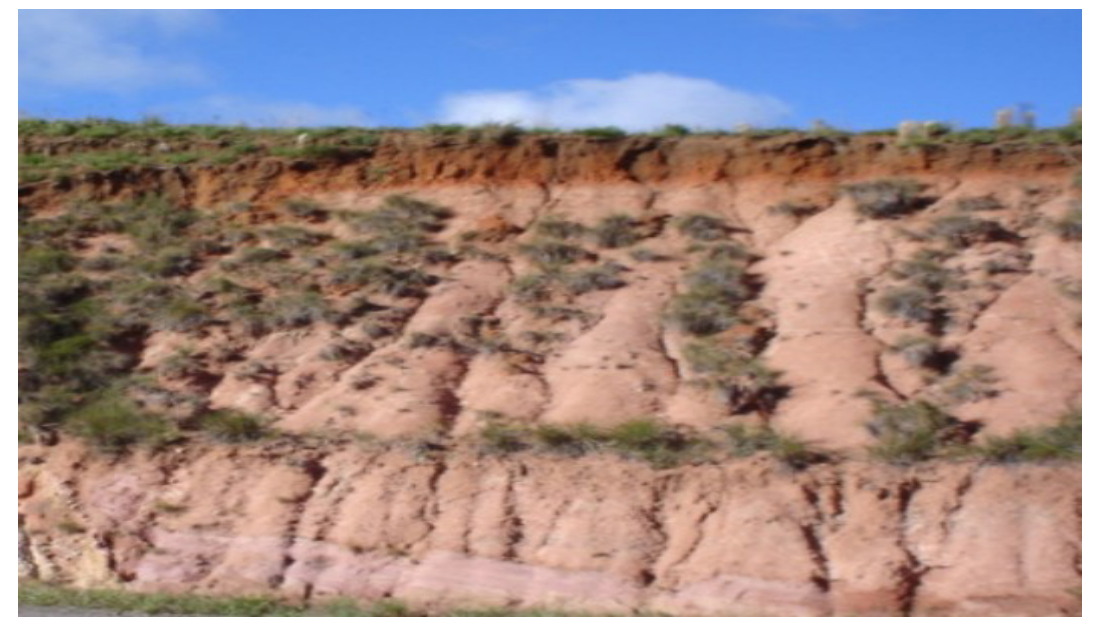

Figura 14. Aspecto da drenagem nos sedimentos da Formação Santa Maria $\left(T_{R} s m\right)$ encravando-se para originar feições erosionais enravinadas que foram denominadas de "sangas" por Bortoluzzi (1974).

Fonte: Trabalho de campo, julho de 2012. 
Tabela 2. Resultados obtidos a partir dos ensaios de compressibilidade para os perfis representativos das formações geológicas no sudoeste do município de São Pedro do Sul, RS.

\begin{tabular}{cccccc}
\hline \multirow{2}{*}{ Formação geológica } & $\mathrm{Ug} \%$ & $\begin{array}{c}\gamma \mathrm{d} \\
\mathrm{gcm}^{-3}\end{array}$ & 1,57 & 145,80 & \multicolumn{3}{c}{ Pré-adensamento } \\
\cline { 4 - 6 } $\mathrm{T}_{\mathrm{R}} \mathrm{rs}$ & 16,88 & $1,5 \mathrm{Ca})$ & 0,20 & $\mathrm{Cr}(\mathrm{e}-03)$ \\
$\mathrm{T}_{\mathrm{R}} \mathrm{C}$ & 19,35 & 1,68 & 157,30 & 0,21 & 2,18870 \\
$\mathrm{~T}_{\mathrm{R}} \mathrm{sm}$ & 16,79 & 1,72 & 145,80 & 0,20 & 1,9850 \\
$\mathrm{Cen}$ & 16,67 & 1,75 & 149,20 & 0,17 & 1,8080 \\
\hline
\end{tabular}

$\mathrm{T}_{\mathrm{R}} \mathrm{sm}=$ Formação Santa Maria; $\mathrm{T}_{\mathrm{R}} \mathrm{rs}=$ Formação Sanga do Cabral; $\mathrm{T}_{\mathrm{R}} \mathrm{c}=$ Formação Caturrita; Cen=Coberturas do Terciário. Fonte: Ensaios em laboratório, 2012.

Dos resultados obtidos a partir dos ensaios de cisalhamento direto, pode-se afirmar que o rompimento do equilíbrio das vertentes está na relação entre a força de ruptura e a coesão do material que constitui o manto de intemperismo. Assim, esse desliza sobre o substrato rochoso (camada R) devido a uma redução na resistência ao cisalhamento. Isso torna-as mais instáveis. Portanto, há uma maior instabilidade morfogenética nas vertentes relativas às formações Santa Maria $\left(T_{R} s m\right)$, Caturrita $\left(T_{R} c\right)$ e coberturas do Terciário (Cen). A figura 13 ilustra o aspecto do perfil de vertentes predominantes na área da Formação Sanga do Cabral, Formação Santa Maria e Formação Caturrita.

A área relativa à ocorrência da Formação Sanga do Cabral ( $\left.\mathrm{T}_{\mathrm{R}} \mathrm{rs}\right)$ é caracterizada por uma topografia suave ondulada, ora com colinas alongadas, ora com mesas sustentadas pelos pacotes essencialmente arenosos. No setor leste e centro da área ocorrem alguns maciços arenosos, constituindo o topo de colinas em nítido contraste com os siltitos da Formação Santa Maria $\left(T_{R} s m\right)$. Suas cotas alcançam 120 a $150 \mathrm{~m}$. Formam uma topografia com morrotes alongados de topo plano, vertentes côncavo-convexas com vales medianamente dissecados. Onde ocorrem sedimentos característicos da Formação Santa Maria $\left(T_{R} s m\right)$, a topografia passa a ser suave com colinas baixas, alongadas na direção dos cursos fluviais entalhantes. Nos sedimentos da Formação Santa Maria $\left(T_{R} s m\right)$, a drenagem encrava-se para originar feições erosionais enravinadas, que foram denominadas de "sangas" por Bortoluzzi (1974). A figura 14 mostra esse aspecto.

A análise dos dados da tabela 1, aliados aos dados da tabela 2, reforça a tese de que a interface entre as formações revela pontos de maior fragilidade às vertentes. Sugerem ainda que na interface entre as formações geológicas, há uma maior freqüência na ocorrência de nichos de nascente e, isso está relacionado com a variação nas propriedades mecânicas (permeabilidade, compressibilidade e cisalhamento) dessas formações. No que se refere ao resultado obtido para os ensaios de compressibilidade (tabela 2), o maior valor relativo à pressão de pré-adensamento $(\mathrm{sp})$ ocorre na Formação Caturrita (TRc), com valores muito próximos para demais formações. A figura 15 ilustra

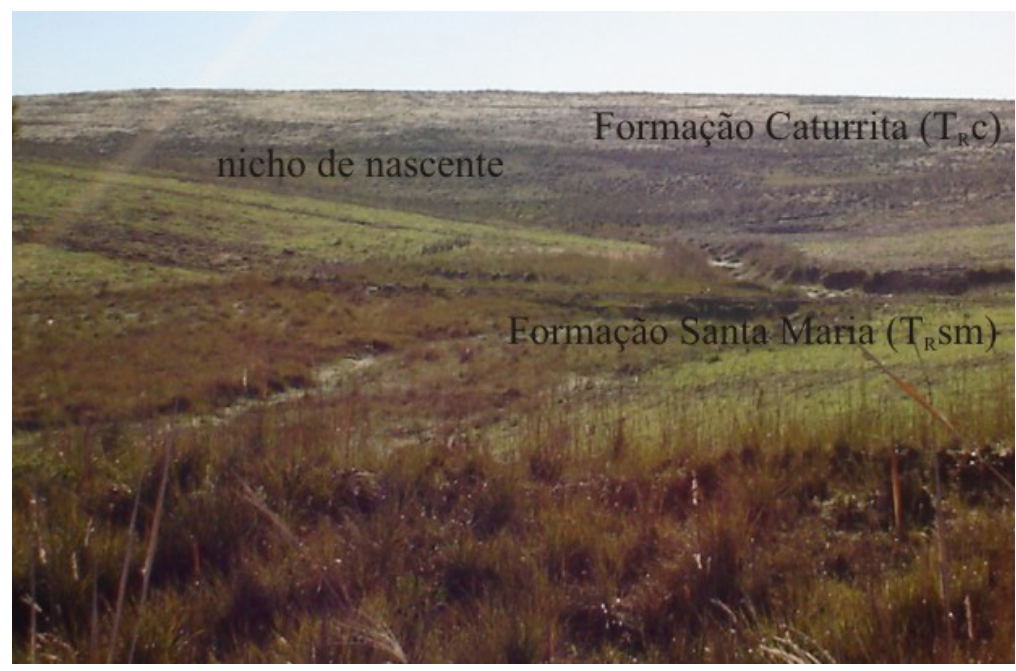

Figura 15: Ocorrência de nicho de nascente na interface entre as formações Santa Maria $\left(T_{R} s m\right)$ e Caturrita $\left(T_{R} c\right)$.

Fonte: Trabalho de campo, julho de 2012. 
Tabela 3. Distribuição do tamanho de poros, micro porosidade, macro porosidade e porosidade total para os perfis representativos das formações geológicas no sudoeste do município de São Pedro do Sul, RS.

\begin{tabular}{cccccccccc}
\hline $\begin{array}{c}\text { Formação } \\
\text { geológica }\end{array}$ & $\begin{array}{c}\gamma \mathrm{d} \\
\mathrm{gcm}^{-3}\end{array}$ & \multicolumn{3}{c}{ Porosidade } \\
\hline & & total & \% micro & macro & $>0,14$ & 0,02 a 0,14 & 0,004 a 0,002 & 0,0001 a 0,004 & $<0,0001$ \\
$\mathrm{~T}_{\mathrm{R}} \mathrm{rs}$ & 1,65 & 50,21 & 44,74 & 5,46 & 3,42 & 5,46 & 7,52 & 10,42 & 73,14 \\
$\mathrm{~T}_{\mathrm{R}} \mathrm{C}$ & 1,66 & 54,36 & 44,14 & 10,22 & 6,18 & 10,22 & 11,60 & 13,88 & 58,09 \\
$\mathrm{~T}_{\mathrm{R}} \mathrm{Sm}$ & 1,67 & 51,25 & 39,05 & 12,20 & 8,10 & 12,20 & 14,94 & 17,48 & 47,26 \\
Cen & 1,69 & 50,41 & 41,02 & 9,39 & 5,75 & 9,39 & 12,60 & 14,98 & 57,25 \\
\hline
\end{tabular}

$\mathrm{T}_{\mathrm{R}} \mathrm{sm}=$ Formação Santa Maria; $\mathrm{T}_{\mathrm{R}} \mathrm{rs}=$ Formação Sanga do Cabral; $\mathrm{T}_{\mathrm{R}} \mathrm{c}=$ Formação Caturrita; Cen=Coberturas do Terciário.

Fonte: Trabalho de campo, julho de 2012.

Tabela 4. Resultados dos ensaios de infiltração para os perfis representativos das formações geológicas no sudoeste do município de São Pedro do Sul, RS.

\begin{tabular}{cllc}
\hline & \multicolumn{3}{c}{ Infiltração } \\
\cline { 2 - 4 } Formação geológica & $\mathrm{cm} /$ segundo & $\mathrm{cm} /$ hora & litros/dia \\
\cline { 2 - 4 } & $1,17892 \times 10^{-8}$ & $4,24412 \times 10^{-5}$ & 1,0185 \\
$\mathrm{~T}_{\mathrm{R}} \mathrm{rs}$ & $8,84192 \times 10^{-8}$ & $3,18309 \times 10^{-4}$ & 7,6394 \\
$\mathrm{~T}_{\mathrm{R}} \mathrm{c}$ & $2,94730 \times 10^{-8}$ & $1,06103 \times 10^{-4}$ & 2,5464 \\
$\mathrm{~T}_{\mathrm{R}} \mathrm{sm}$ & $1,10032 \times 10^{-7}$ & $3,96611 \times 10^{-4}$ & 9,5068 \\
$\mathrm{Cen}$ &
\end{tabular}

$\mathrm{T}_{\mathrm{R}} \mathrm{sm}=$ Formação Santa Maria; $\mathrm{T}_{\mathrm{R}} \mathrm{rs}=$ Formação Sanga do Cabral; $\mathrm{T}_{\mathrm{R}} \mathrm{c}=$ Formação Caturrita; Cen=Coberturas do Terciário.

Fonte: Ensaios em campo.

a ocorrência de nicho de nascente na interface entre as formações Santa Maria (TRsm) e Caturrita (TRc).

Os resultados relativos à distribuição do tamanho de poros, porosidade total, micro e macro porosidade (tabela 3) revelam a Formação Sanga do Cabral $\left(\mathrm{T}_{\mathrm{R}} \mathrm{rs}\right)$ com uma maior quantidade de poros menores e menor quantidade de macroporos. As formações Santa Maria $\left(T_{R} s m\right)$ e Caturrita $\left(T_{R} c\right)$ apresentam maior quantidade de macroporos. Isso revela que estão mais sensíveis às variações de umedecimento e ressecamento sazonal. Essa condição auxilia na explicação do modelado do relevo com formas convexas.

A distribuição do diâmetro de poros mais homogênea, observada para as formações Santa Maria, Caturrita e coberturas do Terciário reforça a tese de que o perfil convexo, predominante na área de ocorrência dessas formações, está relacionado a uma variação sazonal da umidade. Essa variação ocorre de maneira mais incisiva na interface entre as formações.
Os poros muito pequenos são responsáveis por uma maior dificuldade de infiltração da água. A Formação Sanga do Cabral ( $\left.\mathrm{T}_{\mathrm{R}} \mathrm{rs}\right)$ apresenta a maior quantidade de poros menores que $0,0001 \mathrm{~mm}$ e, também, o menor coeficiente de infiltração (tabela 4). Há uma significativa variação no volume infiltrado, sendo que a Formação Sanga do Cabral ( $\left.\mathrm{T}_{\mathrm{R}} \mathrm{rs}\right)$ apresentou o menor volume infiltrado. As coberturas do Tericário (Cen) e a Formação Caturrita $\left(T_{R} c\right)$ apresentaram valores próximos entre si. A Formação Santa Maria $\left(\mathrm{T}_{\mathrm{R}} \mathrm{sm}\right)$, aproximou-se mais dos valores obtidos para a Formação Sanga do Cabral ( $\left.\mathrm{T}_{\mathrm{R}} \mathrm{rs}\right)$.

O comportamento da infiltração reforça a concepção de que os anfiteatros erosivos, presentes em grande número na interface das formações geológicas que ocorrem na área estudada, estão facilitados em sua ocorrência, devido a diferenças na permeabilidade entre essas formações. Dessa forma, as vertentes assumem características relacionadas as propriedades 
mecânicas das formações e das variações entre fácies, no interior dessas, refletindo uma relação de causa e efeito entre a rede de drenagem, o trabalho erosivo e a forma das vertentes.

\section{Conclusão}

O comportamento da resistência ao cisalhamento, revelado pelos maiores valores de coesão para os materiais relativos à Formação Sanga do Cabral $\left(\mathrm{T}_{\mathrm{R}} \mathrm{rs}\right)$, quando comparados as áreas relativas às demais formações, levam a conclusão que essa condição influi na configuração do padrão da rede de drenagem confirmando o pressuposto do trabalho. Os resultados obtidos indicam que as propriedades de resistência ao cisalhamento, compressibilidade e permeabilidade, influenciam o comportamento da rede de drenagem bem como a forma do perfil das vertentes, condicionando a evolução do relevo na área sudoeste do município de São Pedro do Sul, RS. O baixo relevo e a conformação de vertentes côncavas na área correspondente a Formação Sanga do Cabral $\left(\mathrm{T}_{\mathrm{R}} \mathrm{rs}\right)$ contrasta com um relevo mais pronunciado em vertentes com formas convexas, nas áreas das formações Santa Maria $\left(T_{R} s m\right)$ e Caturrita $\left(T_{R} c\right)$, indicando relação com as propriedades de resistência ao cisalhamento, compressibilidade e permeabilidade do material sedimentar dessas formações geológicas.

A resistência ao cisalhamento dos materiais relativos formações Santa Maria $\left(T_{R} s m\right)$ e $\left(T_{R} c\right)$ contribuem para configuração do relevo com topografia mais movimentada e vertentes com perfil de forma convexa. Também a distribuição no tamanho de poros e o comportamento do coeficiente de infiltração, influem os fluxos de água em subsuperfície, indicando as áreas de contato entre essas formações, uma ocorrência freqüente de nichos de nascente em anfiteatros erosivos. Portanto, conclui-se que as propriedades de resistência ao cisalhamento, compressibilidade e permeabilidade, dessas formações geológicas, influem na evolução da rede de drenagem, na forma do perfil das vertentes e na conformação do relevo da área sudoeste do município de São Pedro do Sul, RS.

\section{Referências}

AB'SABER, A.N. Um conceito de geomorfologia a serviço das pesquisas sobre o quaternário. Geomorfologia, São Paulo, n.18, 1969.

BERTRAND, G. Paysage et géographie physique globale: Esquisse méthodologique. Revue
Géographique des Pyrénées et du Sud-Ovest, Toulouse: v 3, n. 39, p. 249-272,1968.

. Paisagem e geografia física global; esboço metodológico. Caderno de Ciências da Terra, São Paulo, n. 13, p.1-27, 1971.

BORTOLUZZI, C.A. Contribuição à Geologia da Região de Santa Maria, Rio Grande do Sul, Brasil. Pesquisas, Porto Alegre, v. 4, n. 1, p.7-86, 1974.

CAPUTO, H.P. Mecânica dos solos e suas aplicações. Rio de Janeiro: Livros Técnicos e Científicos S. A, 1981.

DIAS JUNIOR, M. S. Avaliação quantitativa da sustentabilidade estrutural dos solos em áreas da Copener Florestal Ltda. Relatório Técnico 1999. Lavras, 1999.

FERNANDES, B.; GALLOWAY, H.M.; BRONSON, R.D.; MANNERING, J.V. Efeito de três sistemas de preparo do solo na densidade aparente , na porosidade total e na distribuição dos poros, em dois solos (typic argiaquoll e typic hapludalf). Revista Brasileira de Ciência do Solo, Campinas, n.7, p. 329-333, 1983.

GIL, A. C. Métodos e técnicas de pesquisa social. São Paulo: Atlas, 1999. Disponível em: http:// pt.scribd.com/doc/2367267/DA-SILVA-MENEZES2001-Metodologia-da-pesquisa-e-elaboracao-dedissertacao Acesso em: 08 de julho de 2011.

HILLEL, D. Fundamentals of soil physics. Massachusetts: Academic Press, 1980.

HOLTZ, R.D.; KOVACS, W.D. An introduction to geotechnical engineering. New Jersey: PrenticeHael, 1981.

KÖPPEN, W.. Climatologia: com um estúdio de los climas de la tierra. Publications In: Climatology. Laboratory of Climatology. New Gersey, 1948.

WERLANG, M.K. Configuração da rede de drenagem e modelado do relevo: conformação da paisagem na zona de transição da Bacia do Paraná na Depressão Central do Rio Grande do Sul. 2004. 207f. Tese de Doutorado (Programa de Pós-Graduação em Ciência do Solo)- Universidade Federal de Santa Maria, 2004. 
LEBERT, M.; HORN, R. A method to predict the mechanical strength of agricultural soils. Soil Tillage Res., 19:275-286, 1991.

MONTEIRO, C.A.F. Geossistemas: a história de uma procura. São Paulo: Contexto, 2000.

NETTO, A.L.C.; AVELAR, A. da S. Hidrologia de Encostas na Interface com a Geomorfologia. In: Geomorfologia: Exercícios, Técnicas e Aplicações. Rio de Janeiro: Bertrand Brasil, 1996. p. 03-138.

REINERT, D.J. Santa Maria: CCR, 2003. Programa computacional para cálculo de parâmetros básicos após teste de consolidação. Santa Maria: Disponível em: <http://www/física_e_genese.ufsm. br . Acessado em: 15 nov.2003.

ROSS, J.L. Geografia do Brasil. São Paulo: Edusp, 1996.

SILVA,V.R.; REINERT,D.J.; REICHERT,J.M. Fatores controladores da compressibilidade de um argissolo vermelho-amarelo distrófico arênico típico. II - grau de saturação em água. Revista Brasileira de Ciência do Solo, n.26, p. 9-15, 2002.

SILVA, V.R.; REINERT, D.J.; REICHERT, J.M. Suscetibilidade à compactação de um latossolo vermelho-escuro e de um podzólico vermelhoamarelo. Revista Brasileira de Ciência do Solo, Viçosa, n.24, p. 239-249, 2000.

SILVA, V.R. Compressibilidade de um podzólico e um latossolo em função do estado inicial de compactação e saturação em água. 1999. 98f. Dissertação (Mestrado em Agronomia)Universidade Federal de Santa Maria, Santa Maria: 1999.

SOTCHAVA, V. B. O estudo de geossistemas. Métodos em Questão, São Paulo, p. 27-36, 1982.

VARGAS, M. Introdução à mecânica dos solos. São Paulo: Mcgraw-Hill do Brasil, 1977.

VIEIRA, E.F. Rio Grande do Sul. Geografia física e vegetação. Porto Alegre: Sagra,1984. 